\title{
The business case for hospital-based Behavioral Screening and Intervention
}

\author{
Richard L. Brown* \\ Department of Family Medicine and Community Health, School of Medicine and Public Health, University of \\ Wisconsin-Madison, United States
}

Received: July 17, 2015

Accepted: September 23, 2015 Online Published: September 28, 2015

DOI: $10.5430 /$ jha.v4n6p95

URL: http://dx.doi.org/10.5430/jha.v4n6p95

\begin{abstract}
Under the Affordable Care Act, hospitals are challenged to avoid growing penalties for adverse outcomes, including readmissions, and to adapt to value-based purchasing, where parent organizations will ultimately regard hospital revenues as costs. Hospitals are responding by implementing quality improvement programs, strengthening coordination of care around and after discharge, and enhancing chronic disease management, but many hospitals continue to suffer penalties. An additional response could be to systematically conduct screening and intervention for "upstream" behavioral risks and disorders - smoking, unhealthy drinking and depression - which are associated with admissions, inferior medical and surgical outcomes, readmissions, and ample costs. By increasing smoking quit rates, reducing binge drinking and enhancing depression outcomes, Behavioral Screening and Intervention (BSI) could improve outcomes for various chronic diseases, prevent acute disease and injury, decrease hospital admissions and readmissions, avert surgical complications, and improve hospitals' bottom lines. This article discusses how hospitals could implement BSI and potential benefits, barriers and limitations.
\end{abstract}

Key Words: Cigarette smoking, Alcohol-related disorders, Depression, Mass screening, Health facility administration, Patient readmission, Patient Protection and Affordable Care Act

\section{INTRODUCTION}

The Affordable Care Act and ensuing regulations are changing the playing field for United States hospitals. Medicare penalizes hospitals by up to $1 \%$ of total revenue for high rates of hospital-acquired conditions, $2 \%$ for poor performance on quality metrics, and $3 \%$ for high readmission rates. ${ }^{[1]}$ As of 2015, these financial risks have been offset somewhat by trends toward rising revenues and declines in costs of care for low-income patients, especially in states that expanded Medicaid. However, Medicaid shortfalls and cuts in Medicaid Disproportionate Shared Hospital payments may soon counteract those trends. ${ }^{[2]}$
More important is a shift toward global quality-based reimbursement mechanisms. Medicare recently proposed a bundled payment plan for hip and knee replacements, where hospitals would receive a set fee for all care during a 90-day period and would incur rewards or penalties for performance on quality measures. ${ }^{[3]}$ Under Centers for Medicare and Medicaid Services (CMS) accountable care organizations (ACOs) and ACO-like private-sector contracts, ${ }^{[4,5]}$ hospitals' parent organizations will increasingly regard hospital revenues as costs. The Department of Health and Human Services aims by 2018 that $50 \%$ of Medicare reimbursement will be based on alternative payment models, such as ACOs and bundled payment plans, and $90 \%$ will be tied to quality or value. ${ }^{[6]}$

*Correspondence: Richard L. Brown; Email: rlbrown@ wisc.edu; Address: 1100 Delaplaine Court, Madison, Wisconsin 53715-1840, United States. 
Hospitals have responded to Medicare's initiatives with a variety of quality improvement efforts. Programs for preventing readmissions have strengthened patient and family needs assessment and education, care coordination around and after discharge, post-discharge monitoring and chronic disease management. ${ }^{[7]}$ Various initiatives are aimed at preventing venous and urinary catheter-related infections, ${ }^{\left[{ }^{[8}\right.}$ pressure ulcers, ${ }^{[9]}$ surgical site infections, ${ }^{[10]}$ objects left in patients after surgeries ${ }^{[11]}$ and falls. ${ }^{[12]}$ Nevertheless many hospitals continue to suffer penalties. ${ }^{[13]}$ As pressures grow for improving outcomes, avoiding complications and preventing admissions - not just readmissions - all hospitals will likely benefit by considering additional strategies.

One underused strategy is Behavioral Screening and Intervention (BSI) - a process for systematically identifying and addressing behavioral risks and disorders that often underlie poor health outcomes and high costs - smoking, unhealthy drinking and depression. Ample literature has delineated the prevalence of these conditions among hospitalized patients and their impact on readmissions, other outcomes and costs. This article reviews that literature, delineates the process of BSI, reports data on its effectiveness, suggests how hospitals could implement it, and describes potential benefits, barriers and limitations.

\section{The PREVALENCE AND IMPaCtS OF BE- HAVIORAL CONDITIONS AMONG HOSPI- TALIZED PATIENTS}

\subsection{National surveys}

Two large national studies highlight the prevalence and importance of behavioral health disorders among hospitalized patients in the United States. Boyd et al. analyzed 2001 and 2002 inpatient and outpatient claims for Medicaid recipients with diagnoses of hypertension, diabetes, coronary heart disease, congestive heart failure (CHF) and chronic respiratory disorders. ${ }^{[14]}$ About half (48\% to 54\%) of these individuals had a mental health disorder, $3 \%$ to $6 \%$ had a substance use disorder, and $11 \%$ to $21 \%$ had both a mental health and substance use disorder. Only $24 \%$ to $32 \%$ of individuals had no mental health or substance use disorders. Those with mental health or substance use disorders manifested $45 \%$ to $259 \%$ higher hospitalization rates and $50 \%$ to $167 \%$ higher costs than those without. Those with mental health and substance use disorders manifested 3 to 5 times the rates of hospitalization and 2 to 4 times the total costs of care of those with no behavioral disorders.

The second study was a 2012 national survey, the National Inpatient Sample (NIS), which assessed the prevalence of mental health and substance use disorders among 26.6 million non-maternal and non-neonatal patients admitted to United States civilian hospitals. ${ }^{[15]}$ This study included patients of all payers. Whereas there was a $22.5 \%$ prevalence of diagnosed mental health or substance use disorders in the general adult population, $32.3 \%$ of hospitalized patients had a diagnosed disorder. Among the latter patients, $21 \%$ of hospitalizations had a primary mental health or substance use disorder diagnosis. Mood disorders, such as depression, and alcohol-related disorders were most common. For the remaining $79 \%$ of their hospitalizations, the behavioral diagnoses were secondary. Thus, as in Boyd's study of Medicaid patients, behavioral conditions were associated with higher rates of admissions for behavioral and non-behavioral disorders.

The NIS provided additional information on the financial impacts for hospitals. Of commercial insurance, Medicare and Medicaid, Medicare accounted for the highest proportion of admissions for patients with mental health diagnoses but no substance-related diagnoses (37.4\%). Medicaid accounted for the highest proportions of admissions with mental health and substance-related diagnoses (30.9\%) and admissions with substance-related diagnoses but no mental health diagnoses (29.0\%). Among patients with primary behavioral diagnoses, $13.9 \%$ were uninsured, whereas $6.0 \%$ of all other hospitalized patients were uninsured. ${ }^{[15]}$ Thus, hospitalizations of patients with behavioral disorders are often compensated at lower rates than those without behavioral disorders.

The NIS also provided information on length of stay and charges. Average length of stay for patients with behavioral diagnoses was 6.6 days, as compared to 4.8 days for those without behavioral diagnoses. Paradoxically, the average cost per stay for patients with behavioral diagnoses was $\$ 6,300$, half the cost for those without behavioral diagnoses. ${ }^{[15]}$ On one hand, the low costs of admissions for patients with behavioral disorders would spare hospitals some adverse financial impact under ACO-like contracts. On the other hand, the length and low cost of these stays suggest that the hospitalized patients have little need for intensive diagnostic and treatment services and might have avoided hospitalization with more effective outpatient management for their chronic behavioral and non-behavioral conditions.

\subsection{Depression}

\subsubsection{Admissions}

In a prospective study of community-dwelling men of ages 69 years and up in Western Australia, moderate to severe depressive symptoms were associated with a $22 \%$ increase in hospital admissions and a $65 \%$ increase in hospital days over the next two years. ${ }^{[16]}$ Among patients newly admitted to a home care program in New York State, depression predicted 
earlier hospital admissions. ${ }^{[17]}$

\subsubsection{Readmissions}

Among over 160,000 patients in 11 large United States healthcare systems admitted for heart failure, myocardial infarction or pneumonia between 2009 and 2011, depression was associated with a $40 \%$ higher rate of 30-day readmissions. ${ }^{[18]}$ In a study of 1,418 inpatients at a Boston hospital, ${ }^{[19]}$ 30 -day readmission rates were $12.6 \%$ for the $63 \%$ of patients without depressive symptoms, $19.6 \%$ for the $16 \%$ of patients with mild symptoms, and $21.1 \%$ for the $24 \%$ of patients with moderate to severe symptoms. Emergency department utilization rates within 30 days after discharge were $15.5 \%, 18.2 \%$ and $28.0 \%$, respectively. This study suggests that even mild depressive symptoms, below the threshold for a diagnosis of major depressive episode, can result in 30day hospital and emergency department readmissions. Other studies have found that depression is associated with higher readmission rates for patients with $\mathrm{CHF}$, chronic obstructive pulmonary disease and acute myocardial infarction. ${ }^{[20-22]}$

\subsubsection{Surgical outcomes}

Researchers used a national Medicare claims database to study risk factors for revised total hip arthroplasty among 56,000 patients who underwent initial arthroplasty between 1998 and 2010. Of 29 potential risk factors, including a variety of chronic diseases, depression was the most important, conferring a $64 \%$ higher chance of revision in the next year. $^{[23]}$ In another study of over 290,000 colorectal surgery patients, those with depression had a 0.75 -day longer length of stay than those without. ${ }^{[24]}$

\subsection{Alcohol}

\subsubsection{Admissions and charges}

For individuals of ages 65 and up, alcohol-related hospitalizations are about as common as hospitalizations for myocardial infarctions. ${ }^{[25]}$ In one inner-city hospital, patients' drinking was responsible for over $20 \%$ of intensive care unit admissions, and such patients were more likely uninsured. ${ }^{[26]}$ Among patients hospitalized for pneumonia, alcohol-related diagnoses were associated with higher charges and intensive care unit admissions. ${ }^{[27]}$

\subsubsection{Readmissions}

In the previously mentioned study of 160,000 patients in 11 healthcare systems, substance use disorders were associated with a $24 \%$ higher frequency of 30 -day readmissions. ${ }^{[18]}$ Among 753 Veterans Administration patients admitted for $\mathrm{CHF}$, current alcohol use increased by nearly 6-fold the odds of readmission within one year. ${ }^{[28]}$ For patients admitted to a Level 1 trauma center, alcohol intoxication increased the chances of repeat admissions by $150 \% .^{[29]}$

Published by Sciedu Press

\subsubsection{Outcomes}

Among patients admitted to the same trauma center, chronic alcohol abuse was associated with twice the risk of complications, such as pneumonia and other infections. ${ }^{[30]} \mathrm{A}$ study of over 9,000 Veterans Administration surgeries found that complication rates increased from $5.6 \%$ to $14.0 \%$ in a dose-response manner with higher self-reports of alcohol use. $^{[31]}$

\subsection{Smoking}

\subsubsection{Population health impacts}

Smoking is the leading preventable cause of death in the United States. It contributes substantially to several of the most common reasons for hospital admissions, including respiratory infections, $\mathrm{CHF}$, other cardiovascular disease, chronic obstructive pulmonary disease and cancer. ${ }^{[32]} \mathrm{Sev}$ eral studies have found that asthmatics who smoke have worse symptoms, more frequent exacerbations, more frequent emergency department visits, higher healthcare costs, accelerated decline in lung function, and increased mortality. ${ }^{[33]}$

\subsubsection{Prevalence}

Nationally, the most recent estimates of the prevalence of smoking among the general adult population are $20 \%$ and 24\%. ${ }^{[34,35]}$ Among adult inpatients at San Francisco General Hospital, the biochemically documented prevalence of smoking was $40 \%$ - over 3 times the prevalence in the surrounding city. ${ }^{[36]}$ Hospitalized patients may have a high prevalence of smoking, because smoking generates so much morbidity.

\subsubsection{Readmissions}

In the previously mentioned study of 753 Veterans Administration patients, tobacco use increased by $82 \%$ the odds of readmission within one year for heart failure. ${ }^{[28]}$ Smoking is associated with higher readmission rates for myocardial infarction, ${ }^{[37]}$ hemophilus influenza pneumonia in patients with chronic lung disease, ${ }^{[38]}$ schizophrenia, ${ }^{[39]}$ and complications of hysterectomy, ${ }^{[40]}$ arthoscopic meniscectomy, ${ }^{[41]}$ ventral hernia repair ${ }^{[42]}$ and lower extremity arterial bypass. ${ }^{[43]}$

\subsubsection{Surgical outcomes}

A study comparing surgical outcomes for 82,304 smokers and a matched comparison group found that smoking increases the odds of pneumonia by $109 \%$, unplanned intubation by $87 \%$, mechanical ventilation by $53 \%$, cardiac arrest by $57 \%$, myocardial infarction by $80 \%$, stroke by $73 \%$, superficial incisional infections by $42 \%$, deep incisional infections by $30 \%$, organ space infections by $38 \%$, septic shock by $55 \%$, and death by $38 \% .{ }^{[44]}$ A study of 14,853 Veterans Administration patients who underwent elective surgery found that costs were $4 \%$ higher for smokers than for non-smokers, 
including former smokers. A meta-analysis of 6 studies comparing outcomes of hip arthoplasty for 4,549 smokers and 3,632 non-smokers found that the smokers had 3.05 times the risk of aseptic prosthesis loosening, 3.71 times the risk of deep infection, and 2.58 times the risk of revisions. ${ }^{[45]}$

\section{BSI}

\subsection{Overview}

The process of systematically identifying and addressing behavioral issues in general healthcare settings is called Behavioral Screening and Intervention or BSI. ${ }^{[46]} \mathrm{BSI}$ is in tended for all adult patients, not just high utilizers, as BSI can prevent low utilizers from becoming high utilizers.

BSI focuses especially on smoking, binge drinking and depression, because these conditions: (1) are easily recognized with brief screening questions; (2) are prevalent among American adults; (3) exert substantial influence on health outcomes and costs; and (4) often respond to on-site interventions with favorable changes in behavioral outcomes, general health outcomes and net healthcare costs. BSI is an integrated package of evidence-based, cost-saving smoking screening and cessation services, alcohol screening, brief intervention and referral to treatment (SBIRT) services, and screening and Collaborative Care for depression (described below). BSI can also address other behavioral issues, such as unhealthy diet, physical inactivity and obesity, for which return on investment is uncertain. ${ }^{[47,48]}$

\subsection{The components of BSI}

The first step of BSI is verbal screening - asking patients a series of questions to discern whether they might have behavioral risks or disorders. Table 1 shows the questions recommended for screening. Screening identifies patients who smoke. It identifies patients who are at high risk and need further assessment for a depressive disorder and for an alcohol use disorder or other patterns of unhealthy drinking.

Table 1. Smoking, alcohol and depression screening questions

1. Have you smoked one or more cigarettes in the past month?

Yes

No

2. A standard drink is 12 ounces of beer, 5 ounces of wine, or a 1.5-ounce shot of 80-proof liquor.

Men: $\quad$ On how many days in the past year have you had 5 or more standard drinks?

Women: On how many days in the past year have you had 4 or more standard drinks?

$\square$ None $\quad \square 1$ to $4 \quad \square 5$ to $10 \quad \square 11$ to $20 \quad \square$ More than 20

3. Over the past 2 weeks, how often have you been bothered by little interest or pleasure in doing things?

Not at all Several days More than half the days Nearly every day

4. Over the past 2 weeks, how often have you been bothered by feeling down, depressed or hopeless?

Not at all Several days More than half the days Nearly every day

Note. For item 1, "Yes" is a positive screen for cigarette smoking; For item 2, any response other than "None" is a positive screen for unhealthy alcohol use; For items 3 and 4, point values of responses are added, and a total score of 3 or more is considered a positive screen for depression. Each response of "Not at all” scores zero points; “Several days”, 1 point; "More than half the days”, 2 points; and "Nearly every day", 3 points ${ }^{[49]}$

Brief alcohol and depression assessment involve administering validated questionnaires that categorize patients with regard to the severity of their risk or disorder. The most commonly used alcohol assessment questionnaire is the Alcohol Use Disorders Inventory Test (AUDIT), a ten-item multiplechoice survey developed by the World Health Organization and found accurate across diverse cultures. ${ }^{[50]}$ The Patient Health Questionnaire-9 (PHQ-9) is commonly used for initial depression assessment and for subsequent tracking of response to treatment. ${ }^{[49]}$ AUDIT and PHQ-9 scores cannot be used to make definitive diagnoses. They are useful for guiding feedback to patients and recommendations on next steps - for example, self-management versus referral to specialty-based resources.
For smoking and binge drinking, motivational interviewing (MI) carries the most evidence of effectiveness. ${ }^{[51,52]} \mathrm{MI}$ avoids common pitfalls that provoke rationalization, defensiveness, and resistance, such as unwanted advice, labels, persuasion and scare tactics. Instead MI engages patients empathically and respectfully in identifying and strengthening their own reasons for change, which may relate to health or to other aspects of life. ${ }^{[53]}$ Once patients are committed to change, they are assisted in designing behavior change plans and refining those plans over time as they find necessary to meet their goals. ${ }^{[54]}$

For depression, Collaborative Care is delivered in addition to usual treatment modalities of medication and/or counsel- 
ing. ${ }^{[55]}$ Collaborative Care involves expanding the healthcare team with individuals who educate patients about depression, instill optimism for treatment, help patients overcome barriers to treatment resources, engage patients in behaviors that lift depressive symptoms such as exercising and socializing, proactively contact patients every one to four weeks, help engage patients maximally in implementing their treatment plans, and readminister PHQ-9 questionnaires at least monthly. If serial PHQ-9 scores reveal poor progress, treatment professionals are alerted to the possible need to modify the treatment plan. In addition, it can be helpful for a psychiatrist to review patients' medical records regularly and advise primary care providers on diagnosis and treatment.

\subsection{Outcomes of BSI}

Optimal smoking cessation services increase one-year quit rates from $3 \%$ to $28 \%$. ${ }^{[55]}$ Such services include MI, medications and nine or more sessions of ongoing support. ${ }^{[51,56]}$ The National Commission on Prevention Priorities has rated smoking cessation the third most effective and cost-effective preventive service, behind daily aspirin for cardiovascular prevention and childhood immunizations. ${ }^{[47]}$ Benefits of smoking cessation include longer lifespans and reduced risk for lung cancer, myocardial infarction, stroke and chronic lung disease. ${ }^{[6]}$ After one year of abstinence, long-time previous smokers manifest a $50 \%$ reduction in myocardial infarction and stroke. ${ }^{[33]}$ For patients with CHF, smoking cessation is as beneficial as starting a beta-blocker or an angiotensin converting enzyme (ACE) inhibitor. ${ }^{[57]}$ Compared to patients with chronic obstructive pulmonary disease who continue smoking, those who quit smoking manifest slower declines in lung function. ${ }^{[33]}$

For binge drinking, BSI is most effective for non-alcohol dependent individuals, who comprise $90 \%$ of individuals who drink above recommended healthy limits. ${ }^{[58,59]}$ For such individuals, brief interventions - ideally consisting of an initial 5- to 20-minute session plus one to three follow-up sessions - elicit reductions of $20 \%$ in days of binge drinking, $33 \%$ in injuries, $37 \%$ in hospitalizations $20 \%$ in emergency department visits and a $\$ 523$ one-year reduction in net healthcare costs. ${ }^{[60]}$ A study of disabled Medicaid emergency department patients found a $\$ 4,392$ one-year net reduction in healthcare costs within one year. ${ }^{[61]}$ The National Commission on Prevention Priorities rates alcohol screening and intervention the fourth most effective and cost-effective preventive service, ahead of screening for high blood pressure, diabetes, high cholesterol, and all cancers. ${ }^{[47]}$ Unfortunately, BSI is seldom effective in referring alcohol dependent patients for specialized treatment. ${ }^{[62]}$ Perhaps another approach would be to offer medications (disulfiram, acamprosate and nal- trexone) and counseling for alcohol dependence in general healthcare settings. ${ }^{[63]}$

According to a meta-analysis of 69 randomized controlled trials, Collaborative Care improves the odds of remission from depression by $75 \%$ at 6 and 12 months after treatment initiation. ${ }^{[64]}$ A study of depressed individuals of ages 60 and up found that an initial investment of \$522 in collaborative care reduces net healthcare costs by $\$ 3,363$ over four years. ${ }^{[65]}$ Successful treatment of depression improves quality of life for all patients, and pain and function for patients with arthritis. ${ }^{[6]}$ Collaborative Care for depression, diabetes and heart disease improves outcomes for all conditions. ${ }^{[67]}$

\subsection{BSI implementation}

\subsubsection{Location and integration}

In hospitals, opportune locations for BSI would be inpatient units, emergency departments and pre-operative assessment programs. After discharge, BSI providers at these locations could deliver ongoing support for behavior change either in person or by phone or telehealth. Alternatively, patients could be transferred to BSI providers in affiliated primary care settings.

BSI could fit particularly well in chronic disease management programs and could serve as their framework. All patients could be screened for smoking, alcohol and depression plus additional issues depending on their age, gender and diagnoses. For example, a 70-year-old patient with CHF could also be screened for medication adherence, sodium intake, physical activity level, obesity, eligibility for daily aspirin to prevent myocardial infarction and stroke, and fall risk. MI and behavior change planning could be the approaches for addressing all unhealthy behaviors.

\subsubsection{BSI providers}

In primary care settings, BSI is most effective when delivered by well-trained and dedicated staff members who have ample time to spend with patients. ${ }^{[58,68]}$ The same dedicated staffing model is recommended for emergency departments and pre-operative assessment programs. For inpatients, perhaps individuals who help with discharge planning or chronic disease management could deliver BSI to enhance continuity and minimize fragmentation of care.

Nurses, master's-level behavioral health professionals and bachelor's-level paraprofessionals can deliver BSI. In selecting BSI providers, educational background and clinical experience appear less important than personal attributes, such as empathy, warmth, and a non-judgmental stance. Most individuals do best with an initial two-week training followed by several months of ongoing support and development through case conferences and reviews of audiotaped 
sessions with patients. ${ }^{[58]}$ Software can help ensure high fidelity in service delivery, engage patients, generate summaries for patients and medical records, and collect data for continuous quality improvement and population health management. Limited fee-for-service reimbursement for paraprofessional-administered BSI may be offset by lower compensation, greater satisfaction following BSI protocols and longer retention.

\subsubsection{Barriers and best practices}

Successful implementation of BSI requires clearly enunciated expectations and oversight by administrators, diligent preparation and ongoing attention by managers, and cooperation from providers, nurses and other staff. Therefore all must be educated about BSI. Managers, providers and staff should help plan workflow, documentation protocols, and data collection procedures for plan-do-study-act cycles. Recommended process metrics for those cycles are the proportions of eligible patients who undergo screening, complete appropriate further assessment, and receive appropriate interventions, referral or pharmacotherapy. Suggested outcome metrics are numbers of cigarettes smoked in the past 7 days, days of risky drinking in the prior 4 weeks, and PHQ-9 scores. These process and outcome metrics can be combined to create overall indices reflecting the population-level impact of BSI. ${ }^{[69]}$

As lengths of stay shorten and intensity of service delivery increases, inserting another service into some patients' busy days can be challenging. In emergency departments, BSI can be delivered to most patients while they are waiting for providers or test results. Most patients who are too sick can receive BSI before discharge or during hospitalizations. BSI can be scheduled routinely as a component of pre-operative assessment programs.

Some patients are not good candidates for BSI. Nurses on units where BSI is conducted should alert BSI providers to skip patients who are too ill, have too much pain or discomfort, lack sufficient mental status, or are expected to die soon.

Staff overload is a frequent barrier to systematic and effective BSI. Hiring dedicated BSI providers is key to success.

Occasionally clinicians and staff object to BSI, especially its focus on alcohol, which may seem intrusive and peripheral to the setting's central mission. Some who object engage in binge drinking themselves and find it harmless. Opposition is usually mollified by education on the health risks of binge drinking, the non-judgmental stance of addressing it as any other risk factor, such as high blood pressure, high blood sugar or high cholesterol, explanation that patients are free to decline both to participate and to modify their unhealthy behaviors, and a clear statement that support for BSI is required of all clinicians and staff.

\subsection{Potential downsides}

The downsides to BSI are minimal. The services generate high patient satisfaction ratings. ${ }^{[58]}$ Most negative feedback from patients occurs when BSI is introduced to patients inappropriately or when BSI providers underutilize MI and communicate in ways that evoke defensiveness or resistance.

\section{Discussion}

Many hospitals continue to suffer Medicare financial penalties, despite initiating various programs to prevent readmissions and improve outcomes. Pressures for better outcomes and cost control are expected to accelerate as Medicare expands shared savings programs, institutes bundled payment programs, and strives to base $90 \%$ of reimbursement on value by 2018. Commercial payers will undoubtedly follow suit. Hospitals will need to find new ways to prevent readmissions and complications. Hospitals' parent organizations will have increasingly strong incentives to minimize admissions across the board.

Systematically addressing patients' behavioral issues could help hospitals and their parent organizations meet some of the challenges of value-based reimbursement, as such issues are associated with higher rates of hospital admissions, complications, other poor outcomes and readmissions. Many hospitalized patients smoke, drink excessively and/or have a behavioral disorder, such as depression. Ample research has shown that BSI can help many patients quit smoking, reduce unhealthy drinking and recover from depression. Return on investment for BSI has been demonstrated in primary care settings, and ample return on investment for alcohol screening and intervention is realized within one year. Despite recommendations from numerous authorities, few primary care settings have expanded their teams to deliver BSI in the robust manner necessary for improving health outcomes and reducing costs, because there has been little incentive to do so. Fee-for-service reimbursement for BSI is small, and most cost savings accrue to other entities, such as payers, hospitals and ACOs.

For hospitals and their parent organizations, opportune settings for BSI include inpatient units, emergency departments, pre-operative assessment programs, and feeder primary care settings. Table 2 lists criteria that would make BSI especially advantageous for hospitals. As value-based reimbursement grows, all hospitals and their parent organizations will benefit from the improved health outcomes and cost savings that BSI can deliver. 
Table 2. Criteria that would make Behavioral Screening and Intervention especially advantageous for a hospital

- The hospital is incurring substantial Medicare penalities for readmissions, hospital-acquired conditions and/or performance on quality metrics

- The hospital serves large numbers of patients in accountable care organizations

- The hospital provides large amounts of poorly compensated and uncompensated care

- The hospital has high rates of surgical complications

- The hospital will participate in Medicare's bundled payment program for hip and knee replacements

- The hospital wishes to be prepared for future shifts toward value-based reimbursement and ample time is required to implement new services

- The hospital has a strong sense of mission to deliver the best possible care

In the past, behavioral issues were largely considered peripheral to mainstream healthcare, and behavioral health services were considered cost centers. Value-based financing initiatives are creating strong incentives to address important behavioral determinants of health, recasting behavioral health services as wise investments. Healthcare organizations that take advantage of such investment opportunities will gain a significant competitive edge in the new era of value-based healthcare financing.

\section{CONFLiCTS OF INTEREST Disclosure}

Dr. Brown is owner and CEO of Wellsys, LLC, which offers training and software to help healthcare settings deliver Behavioral Screening and Intervention.

\section{REFERENCES}

[1] American Academy of Medical Colleges. Selected Medicare quality provisions under the ACA. 2015 [Retrieved on September 18, 2015]. Available from: https://www. aamc.org/advocacy/medicare /153882/selected_medicare_hospital_quality_provisi ons_under_the_aca.html

[2] Cunningham P, Garfield R, Rudowitz R. How are hospitals faring under the Affordable Care Act? Early experiences from Ascension Health. Kaiser Family Foundation. April 30, 2015 [Retrieved on September 18, 2015]. Available from: ttp://kff.org/report-section/how-are-hospitals-far ing-under-the-affordable-care-act-early-experienc es-from-ascension-health-issue-brief

[3] Federal Register. Medicare Program; Comprehensive Care for Joint Replacement Payment Model for Acute Care Hospitals Furnishing Lower Extremity Joint Replacement Services. 80 FR 41197. July 14, 2015 [Retrieved on September 18, 2015]. Available from: https://federalregister.gov/a/2015-17190

[4] Department of Health and Human Services (DHHS). Better, smarter, healthier: in historic announcement, HHS sets clear goals and timeline for shifting Medicare reimbursements from volume to value (press release). January 26, 2015 [Retrieved on September 18, 2015]. Available from: http://www.hhs.gov/news/press/2015pres/ 01/20150126a.html

[5] Abelson R. Industry group to back results-focused care. New York Times. January 28, 2015 [Retrieved on September 18, 2015]. Available from: http://www.nytimes.com/2015/01/28/business/ 28payment.html

[6] Department of Health and Human Services (DHHS). The Health Benefits of Smoking Cessation. Centers for Disease Control and Prevention. DHHS publication No. (CDC) 90-8416, 1990 [Retrieved on September 18, 2015]. Available from: http://profiles.nlm.n ih.gov/ps/access/NNBBCT.pdf

Published by Sciedu Press
[7] Rutherford P, Nielsen GA, Taylor J, et al. How-to Guide: Improving Transitions from the Hospital to Community Settings to Reduce Avoidable Rehospitalizations. Cambridge, Massachusetts: Institute for Healthcare Improvement; 2013 [Retrieved on September 18, 2015]. Available from: http://www.ihi.org/resources/Page s/Tools/HowtoGuideImprovingTransitionstoReduceAvoi dableRehospitalizations.aspx

[8] Stone PW, Pogorzelska-Maziarz M, Herzig CT, et al. State of infection prevention in US hospitals enrolled in the National Health and Safety Network. American Journal of Infection Control. 2014; 42: 94-9. http://dx.doi.org/10.1016/j.ajic. 2013.10.003

[9] Zaratkiewicz S, Whitney JD, Lowe JR, et al. Development and implementation of a hospital-acquired pressure ulcer incidence tracking system and algorithm. Journal of Healthcare Quality. 2010; 32: 44-51. http://dx.doi.org/10.1111/j.1945-1474.2010.00076.x

[10] Institute for Healthcare Improvement (IHI). How-to Guide: Prevent Surgical Site Infections. Cambridge, Massachusetts: IHI; 2012 [Retrieved on September 18, 2015]. Available from: http://www.ihi.org/resources/Pages/Tools/Howt oGuidePreventSurgicalSiteInfection.aspx

[11] Treadwell JR. Prevention of surgical items being left inside patient; brief update review (Chapter 15). In: Shekelle PG, Wachter RM, Pronovost PJ, et al. Making Health Care Safer II: An Updated Critical Analysis of the Evidence for Patient Safety Practices. Evidence Report No. 211. AHRQ Publication No. 13-E001EF. Rockville, Maryland: Agency for Healthcare Research and Quality; 2013 [Retrieved September 18, 2015]. Available from: http://www.ncbi.nlm.nih.gov/books/NBK133403/

[12] Ganz DA, Huang C, Saliba D, et al. Preventing falls in hospitals: a toolkit for improving quality of care. AHRQ Publication No. 13-0015-EF. Rockville, Maryland: Agency for Healthcare Research and Quality; 2013 [Retrieved on September 18, 2015]. Available from: http://www . ahrq.gov/professionals/syste ms/hospital/fallpxtoolkit/index.html 
[13] Rau J. Half of nation's hospitals fail again to escape Medicare's readmission penalties. Kaiser Health News, August 3, 2015 [Retrieved on September 18, 2015]. Available from: http://khn.org/news/half-of-nations-hospitals-fai 1-again-to-escape-medicares-readmission-penalties/

[14] Boyd C, Leff B, Weiss C, et al. Clarifying multimorbidity patterns to improve targeting and delivery of clinical services for Medicaid populations. Faces of Medicaid; Data Brief. Hamilton, New Jersey: Center for Health Care Strategies; 2010 [Retrieved on September 18, 2015]. Available from: http://www.chcs.org/resource/face s-of-medicaid-clarifying-multimorbidity-patterns-t o-improve-targeting-and-delivery-of-clinical-servi ces-for-medicaid-populations/

[15] Heslin KC, Elixhauser A, Steiner CA. Hospitalizations involving mental and substance use disorders among adults, 2012. HCUP Statistical Brief \#191. Rockville, Maryland: Agency for Healthcare Research and Quality; 2015 [Retrieved on September 18, 2015]. Available from: https://www.hcup-us.ahrq.gov/reports/s tatbriefs/sb191-Hospitalization-Mental-Substance-U se-Disorders-2012.pdf

[16] Prina AM, Huisman M, Yeap BB, et al. Association between depression and hospital outcomes among older men. CMAJ. 2013; 185: 117-123. http://dx.doi.org/10.1503/cmaj.121171

[17] Sheeran T, Byers AL, Bruce ML. Depression and increased shortterm hospitalization risk among geriatric patients receiving home healthcare services. Psychiatric Services. 2010; 61: 78-80. http: //dx.doi.org/10.1176/ps.2010.61.1.78

[18] Ahmedani BK, Solberg LI, Copeland LA, et al. Psychiatric comorbidity and 30-day readmissions after hospitalization for heart failure, AMI and pneumonia. Psychiatric Services. 2015; 66: 134-140. http://dx.doi.org/10.1176/appi.ps. 201300518

[19] Cancino RS, Culpepper L, Sadikova E, et al. Dose-response relationship between depressive symptoms and hospital readmission. Journal of Hospital Medicine. 2014; 9: 358-364. http: //dx.doi .org/10. 1002/jhm. 2180

[20] Almagro P, Barreiro B, Ochoa de Echaguen A, et al. Risk factors for hospital readmission in patients with chronic obstructive pulmonary disease. Respiration. 2006; 73: 311-317. http://dx. doi .org/10. 1159/000088092

[21] Frasure-Smith N, Lesperance F, Gravel G, et al. Depression and healthcare costs during the first year following myocardial infarction. Journal of Psychosomatic Research. 2000; 48: 471-478. http: //dx.doi.org/10.1161/01.CIR.101.16.1919

[22] Jiang W, Alexander J, Christopher E, et al. Relationship of depression to increased risk of mortality and rehospitalization. Archives of Internal Medicine. 2001; 161: 1849-1856. http://dx.doi.org/1 $0.1001 /$ archinte.161.15.1849

[23] Bozic KJ, Lau E, Ong K, et al. Risk factors for early revision after primary total hip arthroplasty in Medicare patients. Clinical Orthopedics and Related Research. 2014; 472: 449-454. http: //dx.doi.org/10.1007/s11999-013-3081-9

[24] Balentine CJ, Hermosillo-Rodriguez J, Robinson CN, et al. Depression is associated with prolonged and complicated recovery following colorectal surgery. Journal of Gastrointestinal Surgery. 2001; 15: 1712-1717. http://dx.doi.org/10.1007/s11605-011-1 640-5

[25] Adams WL, Yuan Z, Barboriak JJ, et al. Alcohol-related hospitalizations of elderly people: prevalence and geographic variation in the United States. JAMA. 1993; 270: 1222-1225. http: //dx.doi.org/10.1001/jama.1993.03510100072035

[26] Marik P, Mohedin B. Alcohol-related admissions to an inner city hospital intensive care unit. Alcohol and Alcoholism. 1996; 4: 393 -
396. http://dx.doi.org/10.1093/oxfordjournals.alcalc .a008168

[27] Saitz R, Ghali W, Moskowitz MA. The impact of alcohol-related diagnoses on pneumonia outcomes. Archives of Internal Medicine. 1997; 157: 1446-1452. http://dx.doi.org/10.1001/archint e.1997.00440340078008

[28] Evangelista LS, Doering LV, Dracup K. Usefulness of a history of tobacco and alcohol use in predicting multiple heart failure admissions among veterans. American Journal of Cardiology. 2000; 86: 1339-1342. http://dx.doi.org/10.1016/S0002-9149(00 ) $01238-8$

[29] Rivara FP, Koepsell TD, Jurkovich GJ, et al. The effects of alcohol abuse on readmission for trauma. JAMA. 1993; 270: 1962-1964. http://dx.doi.org/10.1001/jama.1993.03510160080033

[30] Jurkovich GJ, Rivara FP, Gurney JG, et al. The effect of acute alcohol intoxication and chronic alcohol abuse on outcome from trauma. JAMA. 1993; 270: 51-56. http://dx.doi.org/10.1001/jama. 1993. 03510010057029

[31] Bradley KA, Rubinsky AD, Sun H, et al. Alcohol screening and risk of postoperative complications in male VA patients undergoing major non-cardiac surgery. Journal of General Internal Medicine. 2011; 11: 162-196. http://dx. doi .org/10.1007/s11606-010-1475-x

[32] Centers for Disease Control and Prevention (CDC). Smoking and tobacco use; health effects of cigarette smoking [Retrieved on September 18, 2015]. Available from: http://www.cdc.gov/tobacco/data_statistics/fact_s heets/health_effects/effects_cig_smoking/index.htm

[33] Wu J, Sin DD. Improved patient outcome with smoking cessation: when is it too late? International Journal of Chronic Obstructive Pulmonary Disease. 2011; 6: 259-267. http://dx.doi.org/10. $2147 /$ COPD . S10771

[34] Centers for Disease Control and Prevention (CDC). Behavioral risk factor surveillance system, prevalence and trends data, nationwide (states and DC) - 2012: tobacco use [Retrieved on September 18, 2015]. Available from: http://www.cdc.gov/brfss/brfsspre valence/index.html

[35] Substance Abuse and Mental Health Services Administration. Results from the 2012 National Survey on Drug Use and Health: detailed tables. Table 2.26B [Retrieved on September 18, 2015] Available from: http://www.samhsa.gov/data/sites/defa ult/files/NSDUH-DetTabsPDFWHTML2013/Web/PDFW/NSDU H-DetTabsSect2peTabs22to26-2013.pdf

[36] Benowitz NL, Schultz KE, Haller CA, et al. Prevalence of smoking assessed biochemically in an urban public hospital: a rationale for routine cotinine screening. American Journal of Epidemiology. 2009; 170: 885-891. http://dx.doi.org/10.1093/aje/kwp215

[37] Shen L, Peterson ED, Li S, et al. The association between smoking and long-term outcomes after non-ST-segment elevation myocardial infarction in older patients. American Heart Journal. 2013; 166: 10561062. http://dx.doi.org/10.1016/j.ahj.2013.09.011

[38] Yadavilli RK, Benson R, Matovu E, et al. Smoking, haemophilus influenzae and hospital readmission. European Respiratory Journal. 2012; 40 (Supplement 56): 2563.

[39] Kobayashi M, Ito H, Okumura Y, et al. Hospital readmission in first-time admitted patients with schizophrenia: smoking patients had higher hospital readmission rate than non-smoking patients. International Journal of Psychiatry and Medicine. 2010; 40: 247-57. http://dx.doi.org/10.2190/PM.40.3.b

[40] Catanzarite TL, Vieira B, Qin C, et al. Risk factors for unscheduled 30-day readmission after benign hysterectomy. Southern Medical Journal. 2015; 108: 524-530. http://dx.doi.org/10.14423/SM J. 0000000000000341 
[41] Basque BA, Gardner EC, Varthi AG, et al. Risk factors for short-term adverse events and readmission after arthroscopic meniscectomy. Does age matter? American Journal of Sports Medicine. 2015; 43: 169-175. http://dx.doi.org/10.1177/0363546514551923

[42] Nelson JA, Fischer J, Chung CC, et al. Readmission following ventral hernia repair: a model derived from the ACS-NSQIP datasets. Hernia. 2015; 19: 125-33. http://dx.doi.org/10.1007/s1002 9-014-1329-2

[43] McPhee JT, Nguyen LL, Ho KJ, et al. Risk prediction of 30-day readmission after infrainguinal bypass for critical limb ischemia. Journal of Vascular Surgery. 2013; 57: 1481-1488. http://dx.doi.org/1 $0.1016 / j \cdot j v s .2012 .11 .074$

[44] Turan A, Mascha EJ, Roberman D, et al. Smoking and perioperative outcomes. Anesthesiology. 2001; 114: 837-846. http://dx.doi.o rg/10.1097/ALN . Ob013e318210f560

[45] Teng S, Yi C, Krettek C, et al. Smoking and risk of prosthesis-related complications after total hip arthroplasty: a meta-analysis of cohort studies. PLOS One. 2015. http://dx.doi .org/10.1371/journ al. pone. 0125294

[46] Brown RL. Configuring healthcare for systematic behavioral screening and intervention. Population Health Management. 2011; 14: 299305. http://dx.doi.org/10.1089/pop. 2010.0075

[47] National Commission on Prevention Priorities. Rankings of Preventive Services for the US Population [Retrieved on September 18, 2015]. Available from: http://www.prevent.org/National -Commission-on-Prevention-Priorities/Rankings-of-P reventive-Services-for-the-US-Population.aspx

[48] Tsai AG, Wadden TA, Volger S, et al. Cost-effectiveness of a primary care intervention to treat obesity. International Journal of Obesity. 2013; 37: S31-S37. http://dx.doi.org/10.1038/ijo. 2013. 94

[49] Babor TF, Higgins-Biddle JC, Saunders JB, et al. AUDIT: The Alcohol Use Disorders Identification Test. Guidelines for Use in Primary Care (second edition). Geneva, Switzerland: World Health Organization; 2001 [Retrieved on September 18, 2015]. Available from: http://apps . who.int/iris/bitstream/1066 5/67205/1/WHO_MSD_MSB_01.6a.pdf

[50] Kroenke K, Spitzer RL, Williams JB, et al. The Patient Health Questionnaire somatic, anxiety and depressive symptoms scales: a systematic review. General Hospital Psychiatry. 2010; 32: 345-359. http: //dx.doi.org/10.1016/j.genhosppsych.2010.03.006

[51] Lai DTC, Cahill K, Qin Y, et al. Motivational interviewing for smoking cessation. Cochrane Database of Systematic Reviews. Art. No.: CD006936; 2010. http://dx.doi.org/10.1002/14651858.CD 006936 . pub2

[52] Field C, Walters S, Marti CN, et al. A multisite randomized controlled trial of brief intervention to reduce drinking in the trauma care setting: how brief is brief? Annals of Surgery. 2014; 259: 873-880. http://dx.doi.org/10.1097/SLA.0000000000000339

[53] Miller WR, Rollnick S. Motivational Interviewing: Preparing People for Change (third edition). New York: Guilford Press; 2013.

[54] Handley M, MacGregor K, Schillinger D, et al. Using action plans to help primary care patients adopt healthy behaviors: a descriptive study. Journal of the American Board of Family Medicine. 2006; 19 : 224-231. http://dx.doi.org/10.3122/jabfm.19.3. 224

[55] Gilbody S, Bower P, Fletcher J, et al. Collaborative care for depression; a cumulative meta-analysis and review of longer-term outcomes. Archives of Internal Medicine. 2006; 166: 2314-2321. http://dx/doi.org/10.1001/archinte.166.21.2314

[56] Agency for Healthcare Research and Quality (AHRQ). Treating Tobacco Use and Dependence: 2008 Update. Clinical Practice Guideline. Rockville, Maryland: Agency for Healthcare Research and
Quality; 2008 [Retreived on September 18, 2015]. Available from: http://www.ncbi.nlm.nih.gov/books/NBK63952/

[57] Suskin N, Sheth T, Negassa A, et al. Relationship of current and past smoking to mortality and morbidity in patients with left ventricular dysfunction. Journal of the American College of Cardiology. 2001; 37: 1677-1682. http://dx.doi.org/10.1016/S0735-1097(01 ) 01195-0

[58] Brown RL, Moberg DP, Allen JB, et al. A team approach to systematic behavioral screening and intervention. American Journal of Managed Care. 2014; 20: e113-e119 [Retrieved on September 18, 2015]. PMid: 24884956. Available from: http://www . ajmc. com/journals/issue/2014/2014-vol20 -n4/a-team-approach-to-systematic-behavioral-scree ning-and-intervention/

[59] Esser MB, Hedden SL, Kanny D, et al. Prevalence of alcohol dependence among US adult drinkers, 2009-2011. Preventing Chronic Disease. 2014; 11: 140329. http://dx.doi.org/10.5888/pcd 11.140329

[60] Fleming MF, Mundt MP, French MT, et al. Benefit-cost analysis of brief physician advice with problem drinkers in primary care settings. Medical Care. 2000; 38: 7-18. PMid: 10630716. http://dx.doi.org/10.1097/00005650-200001000-00003

[61] Estee S, Wickizer T, He L, et al. Evaluation of the Washington State screening, brief intervention and referral to treatment project: cost outcomes for Medicaid patients screened in hospital emergency departments. Medical Care. 2010; 48: 18-24. http://dx.doi.org/1 $0.1097 /$ MLR. Ob013e3181bd498f

[62] Glass JE, Hamilton AM, Powell BJ, et al. Specialty substance use disorder services following brief alcohol intervention: a meta-analysis of randomized controlled trials. Addiction. 2015; 110: 1404-1415. http://dx.doi.org/10.1111/add.12950

[63] Center for Substance Abuse Treatment (CSAT). Incorporating Alcohol Pharmacotherapies Into Medical Practice. Treatment Improvement Protocol (TIP) Series 49. HHS Publication No. (SMA) 09-4380. Rockville, Maryland: Substance Abuse and Mental Health Services Administration; 2009 [Retrieved on September 18, 2015]. Available from: http://www.ncbi.nlm.nih.gov/books/NBK64041/

[64] Thota AB, Sipe TA, Byard GJ, et al. Collaborative care to improve the management of depressive disorders; a community guide systematic review and meta-analysis. American Journal of Preventive Medicine. 2012; 42: 525-538. http://dx.doi.org/10.1016/j .amepre.2012.01.019

[65] Unutzer J, Katon WJ, Fan MY, et al. Long-term cost effects of collaborative care for late-life depression. American Journal of Managed Care. 2008; 14: 95-100 [Retrieved on September 18, 2015]. PMid: 18269305. Available from: http://www.ajmc.com/journals/ issue/2008/2008-02-vol14-n2/f eb08-2835p095-100

[66] Lin EHB, Katon W, Von Korff M, et al. Effect of improving depression care on pain and functional outcomes among older adults with arthritis. JAMA. 2003; 290: 2428-2429. http://dx. doi .org/10 . 1001/jama. 290.18.2428

[67] Katon WJ, Lin EH, Von Korff M, et al. Collaborative care for patients with depression and chronic illnesses. New England Journal of Medicine. 2010; 363: 2611-2620. http://dx.doi.org/10.1056 /NEJMoa1003955

[68] Pietruszewski P, Mundt MP, Hadzic S, et al. Effects of staffing choices on collaborative care for depression at primary care clinics in Minnesota. Psychiatric Services. 2015; 66: 101-103. http: //dx.doi.org/10.1176/appi.ps. 201300552

[69] Brown RL, Smith MA. Population-level quality measures for behavioral screening and intervention. American Journal of Medical Quality. 2015. http://dx.doi.org/10.1177/1062860615577131 